\title{
Structuring socio-technical complexity in infrastructure systems: an agent-based model
}

\author{
Reinier Verhoog* \\ College of Management of Technology, \\ Swiss Federal Institute of Technology in Lausanne (EPFL), \\ Station 5, CH-1015 Lausanne, Switzerland \\ Email: reinier.verhoog@epfl.ch \\ *Corresponding author
}

\section{Amineh Ghorbani}

Faculty of Technology, Policy and Management,

Delft University of Technology,

Jaffalaan 5, 2628 BX Delft, the Netherlands

Email: a.ghorbani@tudelft.nl

\author{
Esther E. Hardi \\ Department of Strategy, \\ Alliander N.V., \\ Utrechtseweg 68, 6812 AH Arnhem, the Netherlands \\ Email: esther.hardi@alliander.com
}

\section{Gerard P.J. Dijkema}

Faculty of Mathematics and Natural Sciences,

University of Groningen,

Nijenborgh 4, 9747 AG Groningen, the Netherlands

Email: g.p.j.dijkema@rug.nl

\section{Margot P.C. Weijnen}

Faculty of Technology, Policy and Management, Delft University of Technology, Jaffalaan 5, 2628 BX Delft, the Netherlands Email: m.p.c.weijnen@tudelft.nl

\begin{abstract}
In this paper we demonstrate how agent-based modelling can be used to understand the emergence of a new infrastructure system, more specifically, a biogas infrastructure in the Netherlands. The innovative element in our modelling approach is the use of MAIA (modelling agent systems using institutional analysis), a meta-model for agent-based modelling of socio-technical systems, to conceptualise and gain insights into the complexity of infrastructure systems. Through our agent-based simulation model we were able to see how the BioNet infrastructure might evolve over three decades,
\end{abstract}


under various conditions of social norms and institutions. We found that current social norms and institutions allow agricultural biogas production to be economically feasible without any subsidies. The simulations also reveal low expected returns on investment and significant risks for farmers in biogas projects.

Keywords: agent-based modelling; complexity; conceptualisation; social simulation; biogas infrastructure; institutional analysis.

Reference to this paper should be made as follows: Verhoog, R., Ghorbani, A., Hardi, E.E., Dijkema, G.P.J. and Weijnen, M.P.C. (2016) 'Structuring socio-technical complexity in infrastructure systems: an agent-based model', Int. J. Complexity in Applied Science and Technology, Vol. 1, No. 1, pp.5-21.

Biographical notes: Reinier Verhoog is a PhD student in the Management of Network Industries chair at the Swiss Federal Institute of Technology in Lausanne (EPFL). He received his MSc in Systems Engineering, Policy Analysis and Management from Delft University of Technology. During his studies, he focused on agent-based modelling and simulation of energy systems. Currently, he is pursuing his research interests by studying the governance of the Swiss energy transition through agent-based modelling and simulation.

Amineh Ghorbani is a post-doc researcher at the Energy and Industry Group of Delft University of Technology, where she also obtained her $\mathrm{PhD}$ in 2013. She has a background in software engineering and artificial intelligence and her expertise is in agent-based modelling and simulation as a decision support tool for policy makers. Her main area of interest is social simulation for understanding the evolution of social structures (e.g., norms, regulations and institutions) in complex socio-technical systems. She has developed agent-based models of various infrastructure systems including e-waste recycling, greenhouses, consumer lighting, biogas, in order to gain insights into how different policy implementations would influence the structural evolution of such systems.

Esther E. Hardi is an Innovation Manager at Alliander, the largest regional and local grid operator for electricity, gas and heat in the Netherlands. For 15 years she has been working in the energy business in the field of competitive strategy, innovation and business development. She graduated in Applied Mathematics at Delft University of Techhnology and started her career with the multinational Schlumberger Offshore. After her international career looking for oil and gas she joined the energy trading company Nuon (Vattenfall) and later the grid operator Alliander and worked in different business units such as trading, retail, business and holding. In recent years, her focus is on biogas, system integration (Power2gas) and optimal renewable energy projects for communities.

Gerard P.J. Dijkema is a Professor of Energy Systems and Industrial Ecology. His experience and research focus is on understanding and modelling of the long-term development of energy infrastructure systems, regional industry and material networks, for the purpose of exploring the effects of innovation, policy and regulation on these complex adaptive systems and the (im)possibilities for their sustainable development. 


\begin{abstract}
Margot P.C. Weijnen is a Full Professor of Process and Energy Systems Engineering at the Faculty of Technology, Policy and Management of Delft University of Technology since 1995. Besides founding the Energy and Industry Group at the TPM Faculty, she is the founding and Scientific Director of the Next Generation Infrastructures Foundation, which represents a cross-sectoral and interdisciplinary knowledge consortium of infrastructure providers and academia in the Netherlands. She has a background in process systems engineering. She obtained her $\mathrm{PhD}$ from TU Delft, then worked for Shell until her appointment in 1990 as a Scientific Director of the Inter-faculty Delft University Clean Technology Institute. Since 2013, she has been a member of the Netherlands Scientific Council for Government Policy (WRR). She is and has been engaged in numerous advisory and supervisory positions to the Dutch Government, the European Commission and Dutch industry.
\end{abstract}

This paper is a revised and expanded version of a paper entitled 'Structuring socio-technical complexity in infrastructure systems: the biogas system' presented at the International Symposium of Next Generation Infrastructure, SMART Infrastructure Facility, University of Wollongong, Australia, 1-4 October 2013.

\title{
1 Introduction
}

Many of today's large scale infrastructures find their origin in local systems, governance, laws and regulation. In the late 19th century, electricity grids in the Netherlands started as local island grids, initially under private ownership, until municipal governments stepped in to provide electricity as a new public utility service. In time, as societal dependence on electricity increased and technology advanced, local municipal systems and regional systems were interconnected to establish national systems, which have since then been interconnected across national borders into the pan-European system that we know today. Along this evolutionary trajectory, the electricity system has become more robust, but its complexity in terms of number and heterogeneity of decision makers involved at various governance levels of the system has also increased. Even now, after more than a century of change, the system continues to evolve as shifting perceptions and goals of stakeholders, translated to new policies, subject infrastructures to a constant pressure to change (Chappin and Dijkema, 2010). An example of this is the goal to reduce $\mathrm{CO}_{2}$ emissions and increase the share of energy supply from renewable sources. As energy systems are characterised by high asset specificity, long asset lifetimes and a limited number of competitors which have a vested interest in maintaining the status quo (Finger et al., 2005), both the technical and the social subsystems of established energy infrastructures pose high barriers to change. At the same time, new policies and institutions that intend to drive established energy infrastructures towards more sustainable outcomes, may create favourable conditions for new infrastructures to emerge.

Biogas distribution by means of existing pipeline systems or dedicated gas grids has started to develop in the Netherlands. Local production facilities have been established, and the first local networks emerge. Biogas infrastructure includes assets for biogas production, distribution, raw-biogas (uncleaned or cleaned for distribution), green gas (biogas upgraded to the quality for gas distribution defined by Dutch law), landfill gas, 
etc. BioNet is a special type of biogas infrastructure, which has been developed by the Dutch distribution system operator Alliander, in which (rudimentary cleaned but not upgraded) biogas is mixed with natural gas to be used in adjusted appliances of end-consumers.

Infrastructure systems, whether mature or emergent, are what Holland (1992, p.19) describes as complex adaptive systems (CAS), since they are made up of many individual elements that interact simultaneously. According to Holland, these systems share the following characteristics: evolution, aggregate behaviour and anticipation. This also holds for energy systems which have evolved over a long period of time. Furthermore, the design and operation of energy systems is not determined by one stakeholder, but rather is distributed amongst multiple stakeholders whose aggregate behaviour determines the systems configuration and performance. This aggregate behaviour cannot be understood by studying the systems' individual elements, because the aggregate behaviour emerges from the interaction between these elements. Unlike technical elements, social elements, such as utility companies, base their current actions on how they anticipate the future. Taken together, these three characteristics make the study of infrastructure systems a challenging task which calls for tools and frameworks to structure this complexity.

In this paper we address how agent-based modelling can be used, in combination with MAIA, a meta-model for agent-based modelling of socio-technical systems (Ghorbani et al., 2013), to better understand the complexity in infrastructure systems. The MAIA meta-model, based on the institutional analysis and development (IAD) framework of Elinor Ostrom, is designed to implement social and technical concepts in agent-based models of infrastructure systems. Van der Lei et al. (2010) developed a framework that illustrates the conceptual compatibility between agent-based modelling and CAS. First, the explicit focus on, and importance of, autonomous agents allows us to structure anticipation in agent decision models. Second, interactions between agents (and other system elements) result in networks that are important for understanding the emergent system behaviour. In agent-based models these network structures are not predefined, but emerge from the interactions between agents, thus reducing the complexity of representing network dynamics. Third, at the system level we can observe the aggregate system behaviour through simulation without predefining system behaviour patterns.

However, building an agent-based model of an infrastructure system is not an easy task as it requires the translation of domain specific knowledge into formalised computer code. Two main challenges hinder a straightforward translation. First, observing the infrastructure system of interest means observing all of its complexity. Second, practitioners with domain-specific knowledge and simulation experts often speak different languages, which complicates the collaborative modelling process. MAIA is useful for modelling infrastructure systems as it not only addresses stakeholders and physical artefacts, but also the policies, regulation and governance of the infrastructure system (Ghorbani et al., 2015). MAIA provides a clear structuring of agent actions which detail the interactions and outcomes necessary to simulate the evolution of an infrastructure system. Furthermore, MAIA provides a high-level language that facilitates the communication and collaborative modelling between practitioners and simulation experts.

Conceptual modelling is a crucial step in the process of creating an agent-based model. First, conceptual modelling bridges the gap between the real world system and the agent-based model, thus supporting effective communication with domain experts and 
policy makers lacking actual modelling experience. Second, performing the conceptualisation step-by-step allows for a rich dialogue between modellers and experts at an early stage in the process. Third, investing time in conceptualisation can result in significant time savings later on in the process. Reaching consensus amongst modelling collaborators as well as unambiguity of the (conceptual) model is important to prevent conflicts and time-consuming model alterations down the road (Nikolic et al., 2012). Finally, many insights and issues are not articulated or written down during this period of innovation and implementation of new techniques and pilots. The conceptual modelling process allows us to document this knowledge, which paves the way for joint learning.

This paper is structured as follows. First, the MAIA meta-model is introduced by detailing its essential components. Second, in order to explain how MAIA can be applied to model an infrastructure system we use the BioNet infrastructure in the Netherlands as a case study. Third, the outcome of the conceptualisation process using MAIA allowed us to create an agent-based model. Fourth, the experimental setup is elaborated. Fifth, the simulation results are presented. The paper concludes with a discussion of the main results and ongoing work.

\section{Modelling infrastructure systems using institutional analysis}

Because infrastructure systems comprise of a large variety of parts we need a wide range of concepts to conceptualise these systems in adequate detail. Meta-models, such as MAIA, offer a high conceptual richness that allows us to conceptualise the physical assets, stakeholders and institutions that make up the infrastructure system (Ghorbani et al., 2013). Furthermore, the concepts are described in a high-level language which makes it easier to elicit practitioners' knowledge. At the same time MAIA has the formal rigor to allow for automatic translation of high-level concepts to executable software, which greatly facilitates the agent-based model building.

Nevertheless, conceptualising the behaviour of individual agents remains relatively difficult (Ghorbani et al., 2013), while social rules and institutions might be more easily understood (Scharpf, 1997). For infrastructure systems social rules and institutions play a central role, which is why MAIA extends and formalises concepts of the IAD framework (Ostrom, 2005), as this framework has been used many times to study institutions in systems including infrastructures (e.g., irrigation systems and the internet) (Ostrom, 2000).

The MAIA meta-model is built up of five interrelated structures, which are described below (Ghorbani et al., 2013). The social rules and institutions are an integral part of MAIA as they constrain and enable the behaviour of other system elements such as physical artefacts, stakeholders, or interactions between system elements. It is through the MAIA structures (Figure 1) that the complexity of socio-technical systems is structured.

- Collective structure: stakeholders are translated into agents by capturing their characteristics and decision criteria based on their perceptions and goals. Agents are autonomous decision making entities. 
- Constitutional structure: stakeholders can perform multiple roles in infrastructure systems. These roles are formalised in the constitutional structure which provides clear rules on who is allowed to perform a certain role. The constitutional structure also enables the conceptualisation of norms, rules and regulation.

- Physical structure: physical artefacts are required to produce, convert, transport and consume goods and together make up the physical infrastructure. Stakeholders (agents) own different parts of the physical infrastructure and their assets can either be open to everyone or only accessible to them.

- Operational structure: stakeholder interactions and decision making are important since they shape the (evolution of the) infrastructure system and determine the system behaviour and performance. Stakeholders interact in the action arena which consists of several action situations where stakeholders perform actions, affected by the system status over time, power shifts, and changing goals and perceptions.

- Evaluative structure: aggregate agent behaviour and system performance are measured and evaluated. The criteria used to evaluate the infrastructure system under study are defined by the observer(s).

Figure 1 MAIA framework

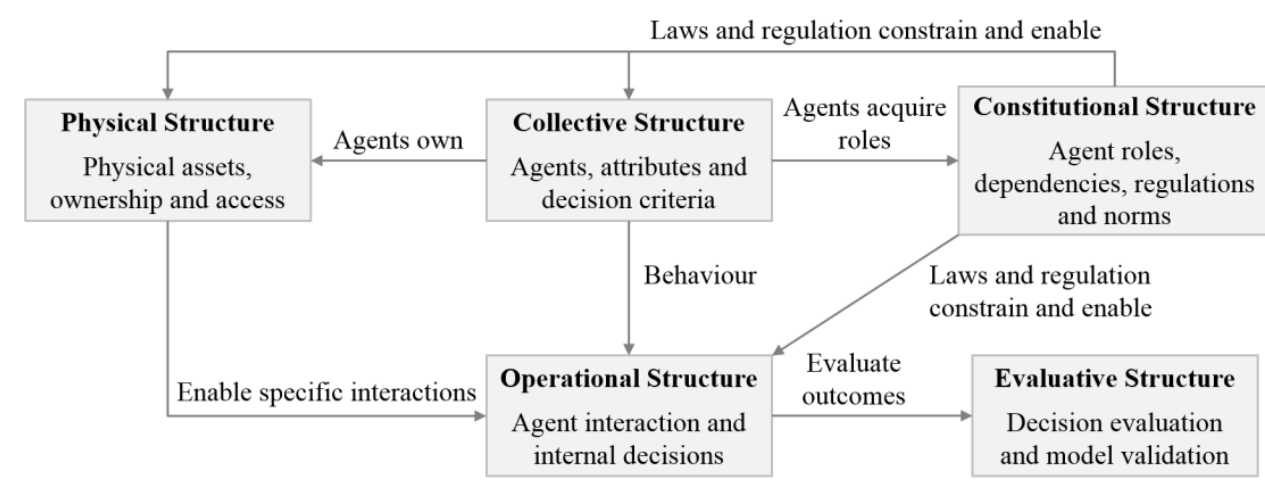

Source: Adopted from Ghorbani et al. (2013)

\section{Biogas infrastructure in the Netherlands}

While the biogas infrastructure in the Netherlands is still in its infancy, it is currently developing at a relatively fast rate. For decades, biogas produced through wet fermentation processes by farmers, industries and waste water treatment facilities has been used to fire local combined heat and power (CHP) units. However, the so-called MEP subsidy that favoured this practice ended in 2008 , forcing biogas producers to identify new feasible business cases for electricity and biogas production. Biogas production by agricultural firms has seen a significant increase between 2005 and 2010, but has since 2010 more or less stabilised (CBS, 2013). Wet fermentation by farmers often uses a mixture of manure and co-feed, since manure produces relative low amounts of biogas. Common co-feeds in the Netherlands are vegetable fat, glycerine, maize silage 
and grain waste (Velghe and Wierinck, 2013). Quite some agricultural firms are currently struggling to earn back their investments, while dealing with high costs of co-feed and digestate (waste product of the wet fermentation process) transport and disposal.

In order to be eligible for renewable energy subsidies in the Netherlands agricultural firms have to convert biogas to electricity or must upgrade it to green gas quality (satisfying the same standards as Groningen natural gas). Both electricity and green gas are typically injected into the local distribution networks for electricity and natural gas, respectively; the agricultural firm is guaranteed a fixed tariff and a subsidy for a certain period of time. Conversion and upgrading require additional assets to be installed, which increases the cost of biogas projects. Furthermore, conversion losses for CHP units can be significant if the produced heat cannot be utilised locally, which is why additional subsidies are awarded if the heat is utilised. Biogas upgrading facilities to green gas are quite expensive and are not always economically feasible at the scale of an individual farmer.

Alliander, a Dutch energy distribution network operator, has developed a technological solution, known as BioNet, to address the reliance on subsidies and the issues of investment costs and conversion losses associated with current biogas projects in the agricultural sector (Hardi et al., 2011). Instead of converting the biogas to electricity, or upgrading it to green gas, it is utilised locally in specialised, robust equipment at the consumer side. This form of biogas production and use appears to be economically viable without subsidies due to lower investment costs for the agricultural firm, lower operational costs and the absence of conversion losses. The only caveat is that a dedicated BioNet distribution grid and mixing installation is required to transport a mixture of natural gas and raw biogas. The end user of the gas needs adjusted household equipment to burn the gas with a wider energy content. Due to the cost for the new equipment a BioNet infrastructure is more likely to be economically feasible in new neighbourhoods where people buy new adjusted equipment. The first BioNet pilot was realised in Eerbeek, the Netherlands in 2013-2014.

A BioNet infrastructure cannot be seen as a stand-alone infrastructure, as it is linked to the natural gas infrastructure (Figure 2). This makes BioNet an interesting case to study from an institutional point of view, because it brings together the currently unregulated biogas domain with the heavily regulated natural gas domain, while increasing the number of stakeholders and physical artefacts. BioNet infrastructure therefore is a prime example of a complex adaptive infrastructure system that may exhibit large evolutionary steps in decades to come.

In this paper we explore the economic feasibility of biogas production and distribution for a BioNet infrastructure without subsidies. We create an agent-based model of a Dutch region encompassing the following municipalities in the Eastern part of the Netherlands: Apeldoorn, Brummen, Deventer, Epe, Lochem, Voorst and Zuthphen. We selected this area since it matches two criteria:

1 abundant agricultural activity and production of manure which can be used in the biogas production process

2 the planned realisation of new neighbourhoods, new industrial parks and a large horticulture complex in the near future. 
Figure 2 The system boundaries encompass local agricultural firms and water treatments that produce biogas and remove harmful substances $(\mathrm{D}=$ digester, $\mathrm{C}=$ cleaner $)$, local agricultural firms that supply manure and BioNets $(\mathrm{M}=$ mixing installation for biogas and natural gas) for new neighbourhoods, industrial parks and large consumers $(\mathrm{B}=$ specialised equipment to burn biogas and natural gas mixture) (see online version for colours)

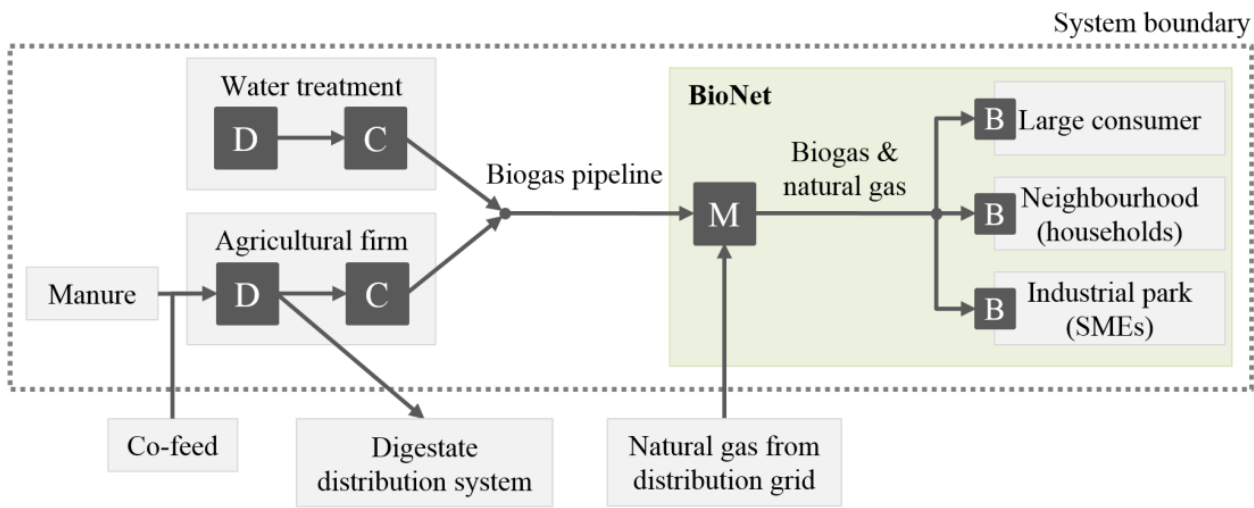

Notes: The geographical boundary of the system comprises of the following municipalities: Apeldoorn, Brummen, Deventer, Epe, Lochem, Voorst and Zuthphen in the Netherlands. Co-feed and natural gas are available in national markets, and are thus considered to be outside of the system boundaries. Digestate (waste product of biogas production) distribution is also considered an external system, but in some cases the digestate can be distributed locally against lower prices.

\section{Modelling the BioNet infrastructure}

In this section, we demonstrate the structuring of complexity of a BioNet infrastructure using MAIA. First we describe the social aspects of this infrastructure using the MAIA constitutional structure since social norms and institutions are central to our analysis. Understanding the regulatory situation of biogas infrastructures helps us understand which stakeholders (MAIA collective structure) and physical assets (MAIA physical structure) are part of the infrastructure. Furthermore, we pay specific attention to the actions of and interactions between stakeholders (MAIA operational structure). We decided to focus on agricultural firms in our analysis, as water treatment facilities have less interactions with stakeholders, and a relatively stable performance in terms of biogas production and profits because they do not require co-feed. A more complete and detailed conceptualisation of the BioNet infrastructure model can be found in Verhoog (2013).

\subsection{Constitutional structure}

The biogas sector is currently not regulated like the natural gas sector, which implies that any player can enter the market and start producing biogas.

However, energy distribution companies are prohibited by Dutch law to engage in any activities other than development and operation of a biogas distribution grid. This is a consequence of the radical ownership unbundling in the Dutch gas and electricity 
markets, which separated transmission and distribution from commercial activities, such as the production of biogas and electricity and the supply of energy services to end-users.

For other stakeholders, such as agricultural firms, there is an opportunity to enter the market of biogas production. It is important to note that these stakeholders acquire the role of biogas producer when they decide to enter the market, a role they were initially not familiar with. Rules and regulations regarding agricultural biogas production were implemented independently of the agricultural firm agents, allowing the agents to adopt or discard the role of biogas producer depending on the situation unfolding. From structuring the rules and institutions that apply to agricultural biogas producers we can gather a lot of information and starting points for structuring the stakeholders (Section 4.2, collective structure) and physical assets (Section 4.3, physical structure).

\subsection{Collective structure}

We have implemented five different agents in our agent-based model: agricultural firm agents, water treatment agents, neighbourhood agents, industrial park agents and large consumer agents. Below we only detail the conceptualisation of agricultural firm agents using the Collective Structure, but all agent conceptualisations can be structured in the same way using MAIA. First, we specify the characteristics that are required to represent agricultural firms within the system boundaries:

- The location $[\mathrm{x}, \mathrm{y}]$ of agricultural firms, relative to other agents, is important for determining the required infrastructural investments and feasibility of the business case.

- Manure [ton/year] is produced by many, but not all, agricultural firms. Manure is an important input for biogas production and if the agricultural firm does not produce enough manure it has to acquire it locally.

- The economic performance of the agricultural firms is determined by their balance $[€]$. Agricultural firms can take out a loan for investments, but will have to make a return on investment.

If an agricultural firm is considering to enter the biogas market it will have to make a strategic investment decision on physical assets such as a digester, cleaner and biogas pipeline. Furthermore, contract negotiations and the establishment of a contract are an important step in realising a biogas project. These choices and interactions are detailed in the operational structure in Section 4.4.

\subsection{Physical structure}

Physical assets play an important role in the simulation model, as their characteristics and operation determine, in large part, the biogas system performance. We detail the conceptualisation of digesters, cleaners and biogas pipelines as these physical assets are closely related. The dimensioning of assets is largely based on long-term contracts between biogas producers and consumers, as standard contracts to feed-in biogas are not available at this moment (unlike the feed-in of green gas). The assets were conceptualised using the MAIA physical structure as follows: 
- Digesters: capacity [ton/year] is the amount of manure and co-feed that can be converted to biogas in a year; efficiency $\left[\mathrm{Nm}^{3} / \mathrm{ton}\right]$ is higher for larger digesters; methane yield $[\%]$ is used to determine the calorific value of the produced biogas; investment costs [€/ton/year] are determined mainly by the capacity and economies of scale in construction; operation and maintenance costs $\left[€ / \mathrm{Nm}^{3} /\right.$ year]; asset lifetime [year], which is assumed to be 15 years in our simulation; location $[\mathrm{x}, \mathrm{y}]$ is used to construct the biogas pipeline network; owner [string] determines which agent owns and operates the asset.

- Cleaners: these are dimensioned accordingly the digesters to which they are connected. Multiple biogas producers can share a cleaner to achieve economies of scale. Capacity $\left[\mathrm{Nm}^{3} /\right.$ year $]$ is the amount of biogas that can be cleaned in a year; investment costs $\left[€ / \mathrm{Nm}^{3} /\right.$ year] is determined mainly by the capacity and economies of scale in construction; operation and maintenance costs [€/ $\mathrm{Nm}^{3} /$ year]; asset lifetime [year], which is assumed to be 15 years in our simulation; location [x, $\mathrm{y}]$ is used to construct the biogas pipeline network; Owner [string] determines which agent owns and operates the asset. These assets can have multiple owners (shared asset).

- Biogas pipelines: these are dimensioned so as to match the production facilities to which they are connected. Multiple biogas producers can share a pipeline to achieve significant economies of scale. Capacity $\left[\mathrm{Nm}^{3} /\right.$ year $]$ is the amount of biogas that can be transported in a year; investment costs $\left[€ / \mathrm{Nm}^{3} / \mathrm{km}\right]$ are mainly determined by the distance due to significant economies of scale in construction; operation and maintenance costs [€/ $\mathrm{Nm}^{3} /$ year]; asset lifetime [year], which is assumed to be 30 years in our simulation; starting point $[\mathrm{x}, \mathrm{y}]$ and end point $[\mathrm{x}, \mathrm{y}]$ are used to determine the length of the pipeline; owner [string] determines which agent owns and operates the asset. These assets can have multiple owners (shared asset).

In an unregulated market these assets are owned and operated by the biogas producers, which means that agricultural firms are faced with multiple operational decisions after adopting the role of biogas producer, as detailed in Section 4.4.

\subsection{Operational structure}

The operational structure of MAIA is used to structure and conceptualise agent behaviour and interactions. These interactions can result in new linkages between the collective, constitutional and physical structures. Three action situations are described which respectively lead to a change in the constitutional structure, a change in the physical structure and no changes in any of the other MAIA structures.

\subsubsection{Collaboration action situation: finding partners to reduce biogas project costs}

Biogas production and consumption are largely local since the transportation infrastructure costs over long distances are prohibitive. Economies of scale play an important role in limiting the investment and operational costs of biogas production. For this reason, agricultural firms will strive to share investment costs. The decision is simple: if an agricultural firm is interested in biogas production, if other interested 
agricultural firms are located nearby, and if the production of biogas is technically feasible for all firms, then they will collaborate.

\subsubsection{Biogas contract negotiations action situation: setting a quantity and price for biogas production}

The model focuses on the amount of biogas production as well as the economic performance of biogas producers. Generally, water treatment plants perform well economically as they can produce biogas at a cost as low as $0.05\left[€ / \mathrm{Nm}^{3}\right]$ (Lensink et al., 2012). The internal decision model of the biogas producer is mainly based on the expected costs and profits of biogas production. The decision model of consumer agents is based on the value of natural gas and the reduction of $\mathrm{CO}_{2}$ emissions that will be accomplished by consuming biogas instead of natural gas. The contract is made for a long period of time (assumed to be 15 years in our simulation) to cover the economic lifetime of the biogas production assets. Once a quantity and price are agreed upon, the physical assets will be built and be available for biogas production in the next year.

\subsubsection{Biogas operation action situation: maximising operational profit}

The operation of biogas production artefacts is driven by the operational costs and expected profits only. Fixed costs are incurred no matter what the biogas producer does. Water treatment plants have low variable costs due to their access to a constant feedstock for 'free', and hence are assumed to make an operational profit for the duration of their contracts. Agricultural firms are dependent on co-feed prices, natural gas prices and $\mathrm{CO}_{2}$ prices. Co-feed prices are volatile and can result in large operational losses (or profits) for agricultural firms. Shut down and start-up costs of biogas production assets are high, as well as contractual fines, which means that not producing any biogas is often not an option.

\section{Experimentation}

In order to assess the feasibility of biogas production we need to consider multiple factors that are exogenous to the biogas system. First, the purchase of co-feed makes up a significant share of the operational costs (Velghe and Wierinck, 2013), but there is uncertainty about the current and future co-feed price. In the $2013 \mathrm{SDE}+$ subsidy report for the Netherlands, the price range for co-feed was between 14 and 32 [ $€ /$ ton], and co-feed prices have been very volatile over the past years (Lensink et al., 2012). Second, the willingness to pay for biogas depends heavily on the price of natural gas and that of $\mathrm{CO}_{2}$ certificates, which are both highly uncertain over the long-term. For example, the Global Economy scenario by ECN (Wakker et al., 2006) forecasts an increasing natural gas price, while the European Market scenario of the World Bank (2013) predicts a decreasing natural gas price. Additional scenarios can be found with similar or divergent predictions, but instead we choose to use the two mentioned scenarios and their average to explore a wide range of natural gas market prices. European Commission (2011) identifies three $\mathrm{CO}_{2}$ certificate price scenarios. Third, the biogas market is currently not regulated, but this might change in the future. If the biogas market is regulated with a similar model as the natural gas market, then biogas production and transport 
infrastructure are likely to be unbundled and grid costs may be socialised. An overview of all model parameters and their possible values are given in Table 1.

The conceptual model was implemented using NetLogo 5.0.4, a multi-agent modelling environment (Wilensky, 1999). We run the agent-based simulation with 108 scenarios to explore all the possible combinations of model parameters. Each simulation runs for 30 ticks (years) to reveal long-term system behaviour, because we study a system with long asset-lifetimes. The simulation starts in 2010 and uses real market prices and biogas demand for that year, while future prices are based on the identified scenarios.

Table 1 Model parameters and values

\begin{tabular}{lccc}
\hline Parameter & & Possible values & \\
\hline Co-feed price & $-2 \% /$ year & Constant & $+2 \% /$ year \\
Initial co-feed price & $14 € /$ ton & $32 € /$ ton & \\
Natural gas price & Strong increase & Moderate decrease & Strong decrease \\
$\mathrm{CO}_{2}$ price & Slight increase & Moderate increase & Strong increase \\
Biogas grid costs & Socialised & Unregulated & \\
\hline
\end{tabular}

\section{Simulation results}

In this section, we present the simulation results and pay specific attention to emergent system behaviour resulting from the aggregated agents' decision making. The aggregate system behaviour is the result of agent decisions and interactions as conceptualised in Section 4 and the scenarios in Section 5. We use the evaluative structure of MAIA to define outcomes of interest and to determine which agent actions and interactions in the operational structure contribute to the outcomes of interest, allowing us to better understand the aggregate behaviour.

Table 2 BioNet model parameter sensitivity

\begin{tabular}{lll}
\hline Parameter & \multicolumn{1}{c}{$\begin{array}{c}\text { Agricultural biogas production } \\
\text { [Nmlyear] }\end{array}$} & \multicolumn{1}{c}{$\begin{array}{c}\text { Average profits } \\
\text { [€/year] }\end{array}$} \\
\hline Co-feed price & $\begin{array}{l}\text { High sensitivity. Negatively impacts } \\
\text { biogas production. }\end{array}$ & $\begin{array}{l}\text { Moderate sensitivity. } \\
\text { Negatively impacts profits. }\end{array}$ \\
Natural gas price & $\begin{array}{l}\text { Highest sensitivity. Positively impacts } \\
\text { biogas production. }\end{array}$ & $\begin{array}{l}\text { Highest sensitivity. } \\
\text { Positively impacts profits. }\end{array}$ \\
$\mathrm{CO}_{2}$ price & $\begin{array}{l}\text { High sensitivity. Positively impacts } \\
\text { biogas production. }\end{array}$ & $\begin{array}{l}\text { Low sensitivity. } \\
\text { Positively impacts profits. }\end{array}$ \\
Biogas grid costs & $\begin{array}{l}\text { Low sensitivity. Socialisation positively } \\
\text { impacts biogas production. }\end{array}$ & $\begin{array}{l}\text { Low sensitivity. } \\
\text { Socialisation positively } \\
\end{array}$ \\
\end{tabular}

Source: Verhoog (2013) 
Figure 3 Visualisation of the BioNet infrastructure after ten years (see online version for colours)

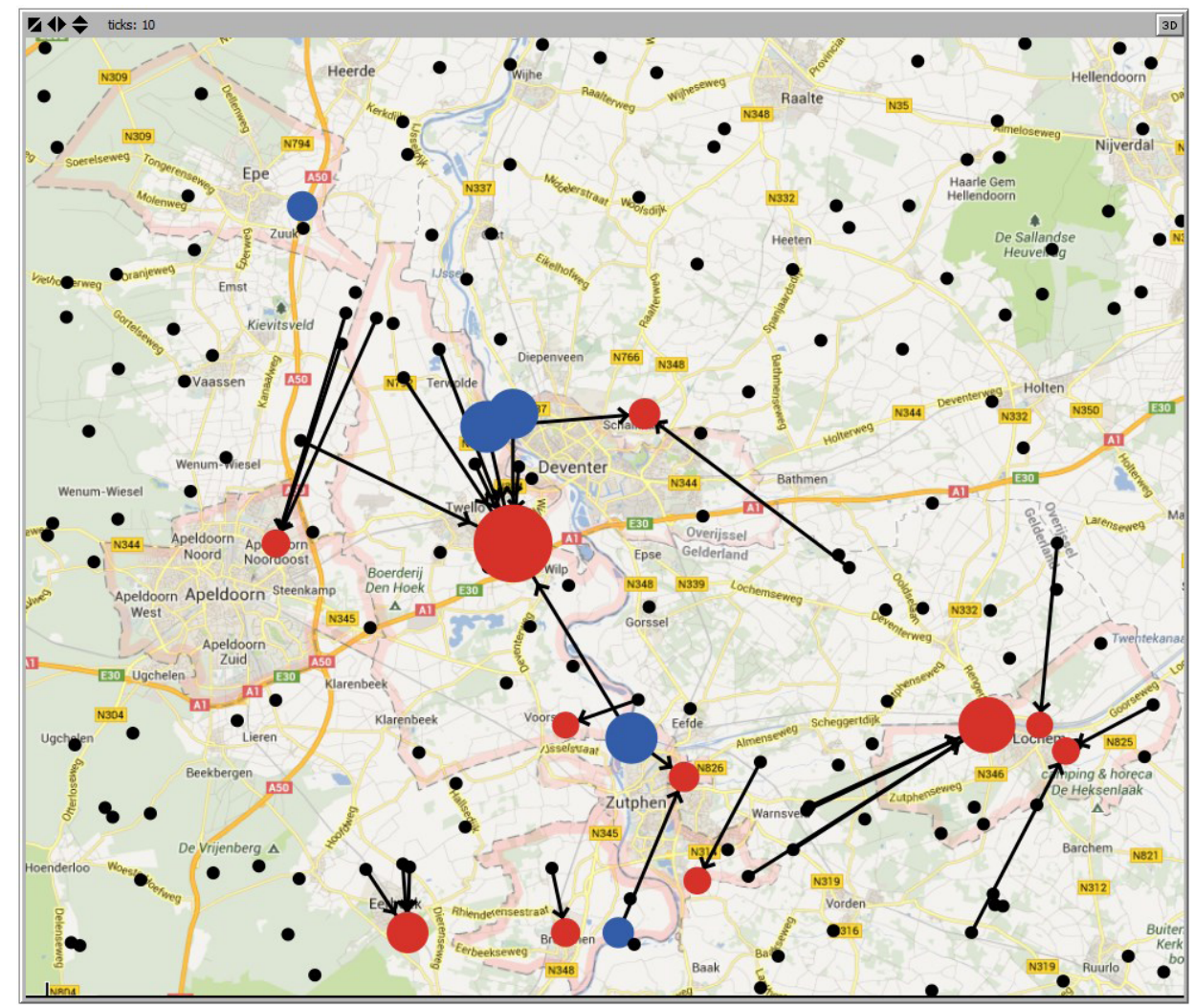

Notes: Agricultural biogas producers are small black circles, water treatment plants are blue circles and biogas consumers are red circles. The black lines represent the delivery of biogas from the producers to the consumers, but the underlying infrastructure (cleaners and pipelines) can be shared when producers are located nearby. This visualisation helps us to understand that (1) distance is important, as the water treatment plant in the top left is not producing any biogas, (2) not all agricultural firms are willing to produce biogas which can result in larger distances over which the biogas is transported.

Together with experts of Alliander we determined two main outcomes of interest: biogas production $\left[\mathrm{Nm}^{3} /\right.$ year] and profits [€/year] of agricultural firms. We found that both outcomes of interest were highly sensitive to co-feed prices, natural gas prices and $\mathrm{CO}_{2}$ prices. The socialisation of grid costs has a low impact on the biogas production and profitability. An overview of the model sensitivity is given in Table 2. Additionally, the model sensitivity for all parameters is indicated using contour plots in Figure 4 and Figure 5. For the validation of our model we used expert validation by presenting the simulation outcomes to experts at Alliander. The simulation outcomes were judged to be plausible.

From the simulation results we can make three interesting observations. First, the biogas system performance, in terms of agricultural biogas production and profits, is very sensitive to the market prices of co-feed, natural gas and $\mathrm{CO}_{2}$. This means that the performance is largely determined by exogenous conditions. This parameter sensitivity 
can be observed from Figures 4 and 5 as well, which shows the model sensitivity to the various scenarios. Changes in aggregate behaviour of agricultural firms can be observed after significant price changes. First and foremost, additional investments in biogas projects or lack of re-investments can be observed when prices are favourable or unfavourable, respectively. In more extreme cases, for example a large increase in co-feed prices in combination with low natural gas and $\mathrm{CO}_{2}$ certificate prices, we observe agricultural firms stop their biogas production in order to reduce their financial losses. A lack of re-investments or biogas producers stopping their production entirely leaves behind a legacy infrastructure of pipelines, which have a lifetime beyond that of the biogas project. Figure 3 provides more insights in the geographical distribution of production and consumption, and gives an indication of the physical infrastructure of the BioNet.

Second, biogas production for a BioNet infrastructure can be economically feasible without any subsidies in a large number of scenarios. However, the expected return on investment (average over all scenarios) is negative and there is a high risk associated with investments in biogas projects given the uncertainty of future market prices. The impact of biogas grid costs on the economic feasibility of biogas projects is much smaller, but can help in getting some projects off the ground. This raises the question whether agricultural firms should invest in biogas projects without subsidies. Different governance structures might increase the value of BioNet projects and reduce the risk for (often small) agricultural firms, as risks could be shared among project or platform partners. These different governance structures for BioNets are explored in a parallel project (Oey et al., 2014).

Figure 4 Total yearly biogas production by agricultural firms

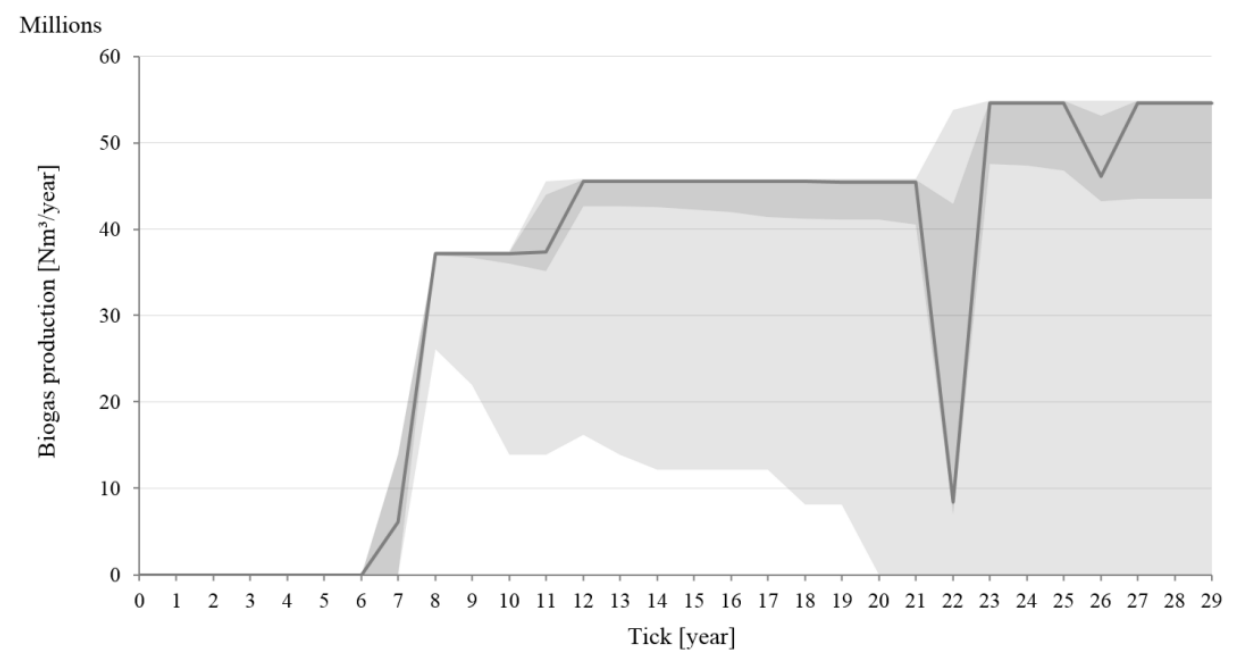

Notes: The thick grey line is the median value of biogas production. The dark grey area contains $50 \%$ of the scenario outcomes and the light grey area contains the remaining $50 \%$ of the scenario outcomes. 
Figure 5 Average yearly profits of agricultural firms

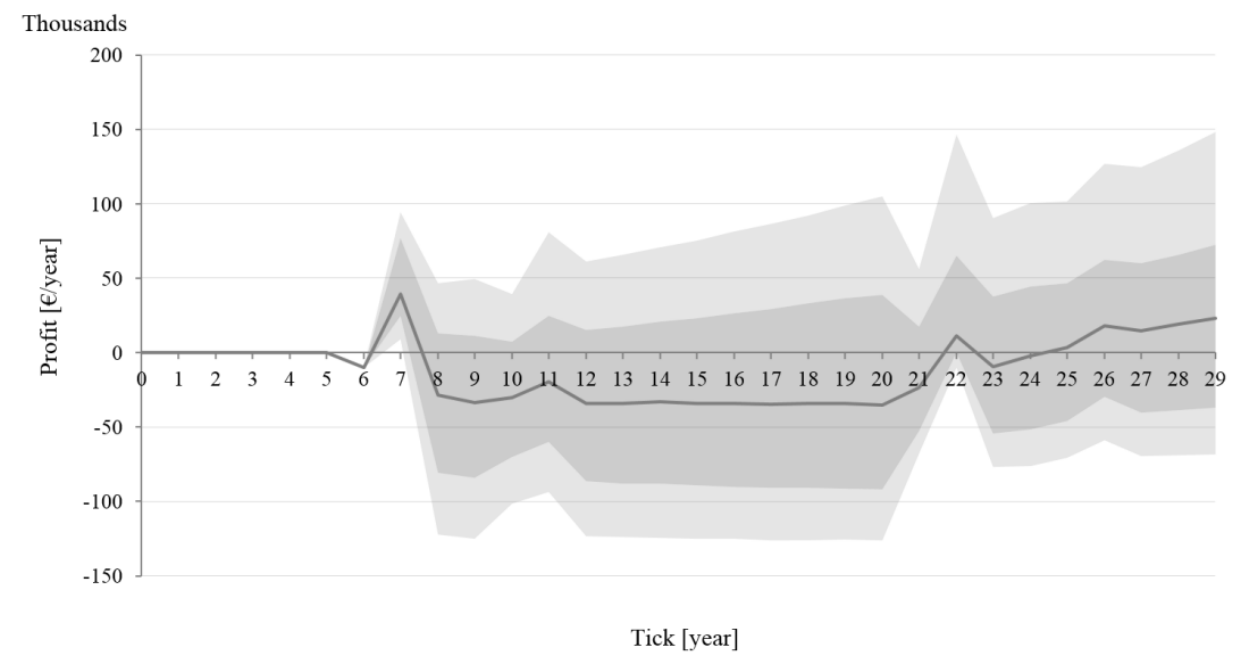

Notes: The thick grey line is the median value of yearly profits. The dark grey area contains $50 \%$ of the scenario outcomes and the light grey area contains the remaining $50 \%$ of the scenario outcomes.

Third, the maximum biogas production is reached in a majority of the scenarios, which is initially around 46 million $\left[\mathrm{Nm}^{3} /\right.$ year] and further into the future around 54 million $\left[\mathrm{Nm}^{3} /\right.$ year]. The shock in biogas production that can be observed between ticks 21 and 23 is because of delayed reinvestments by biogas producers, which can be explained by the relatively poor economic performance that many projects were facing during prior years. However, $\mathrm{CO}_{2}$ prices are expected to increase in the future, which makes many biogas projects economically viable in the long run.

\section{Conclusions and future work}

At the case study level, the contribution of this paper is a deeper insight into the factors determining the economic feasibility of agricultural biogas production in BioNets in the Netherlands. We found that agricultural biogas production can be economically feasible without any subsidies, albeit with a low expected return on investment, and that significant risks are involved in biogas projects. The investment risks result from highly uncertain future prices for co-feed, for natural gas and for $\mathrm{CO}_{2}$ certificates, all of which have a significant impact on the profits of agricultural firms. Current social norms and institutions work out so that these risks are distributed to (small) agricultural firms. We found that socialising the biogas pipeline costs over the consumers does not have a high impact on the biogas production and economic performance of agricultural firms. However, different governance structures (e.g., full or partial ownership of biogas production and distribution assets by the consumers) could more effectively redistribute the risks between stakeholders. Once established, long asset-lifetimes and long-term contracts render stability to the BioNet infrastructure system for years, even if the economic performance of the agricultural firms involved is poor. 
At the methodological level, the contribution of this paper is the successful demonstration of the MAIA meta-model in conceptualising the multi-dimensional complexity of infrastructure systems, more specifically, the emerging BioNet infrastructure in the Netherlands. The high-level language of MAIA facilitated the elicitation and documentation of expert knowledge from (non-)technical practitioners, allowing for joint-learning between modellers and practitioners. The structural concepts in MAIA were successfully used to conceptualise and build an agent-based simulation model of the BioNet infrastructure. The support that MAIA offered in structuring the complexity of the BioNet case confirms the conceptual richness of MAIA and adds to the evidence that MAIA can indeed facilitate the conceptualisation of a wide range of socio-technical systems [e.g., consumer lighting transition, wood-fuel market, e-waste recycling, and manure-based biogas production (Ghorbani, 2013)]. Through a variety of simulation runs, we were able to see how the BioNet infrastructure might evolve over three decades, based on the conceptualised behaviour of individual agents under various conditions of social norms and institutions. Particularly important in the modelling process was the conceptualisation of the spatial and institutional dimensions of the biogas system, supported by the physical and constitutional structures of MAIA. For any infrastructure system, modelling of these dimensions is of crucial importance, as physical artefacts and institutions have relatively long-lasting effects on the structure of socio-technical systems in comparison with other system elements that are changing faster.

We identify three directions for future research. First, while the biogas infrastructure is interconnected with the natural gas infrastructure, the natural gas infrastructure was largely excluded from the BioNet model. Studying the unfolding of co-evolutionary processes between different infrastructures significantly increases modelling complexity due to the larger number of social and technical system elements that simultaneously interact. MAIA concepts and Structures are expected to be particularly helpful in structuring and conceptualising such co-evolutionary processes, as we hope to demonstrate in the future.

Second, the conceptual biogas model presented in this paper has been implemented by different modellers. The BioNet model in this paper was implemented using NetLogo. In a parallel research project, the model was implemented using Agentscape (Oey et al., 2014). Both model implementations are based on one and the same conceptual BioNet model. However, the two models have not been compared yet in terms of structure or model output. Future work will focus on the comparison of the two model implementations.

Third, the cost and feasibility of BioNet and biogas infrastructure in general are largely dictated by the geographical distribution of production locations and their vicinity to the existing natural gas distribution network. To study this effect, the conceptual model must be implemented using geo-spatially explicit representations of producers, consumers and the established gas networks.

\section{References}

CBS (2013) Hernieuwbare Energie in Nederland 2012.

Chappin, E.J.L. and Dijkema, G.P.J. (2010) 'Agent-based modelling of energy infrastructure transitions', International Journal of Critical Infrastructures, Vol. 6, No. 2, pp.106-130. 
European Commission (2011) Impact Assessment Annex 1 Scenarios - Assumptions and Results, Brussels.

Finger, M., Groenewegen, J. and Künneke, R. (2005) 'Quest for coherence between institutions and technologies in infrastructures', Competition and Regulation in Network Industries, Vol. 6, No. 4, pp.227-260.

Ghorbani, A. (2013) Structuring Socio-technical Complexity - Modelling Agent Systems using Institutional Analysis, $\mathrm{PhD}$ thesis, Delft University of Technology.

Ghorbani, A., Bots, P.W.G., Dignum, V. and Dijkema, G.P.J. (2013) 'MAIA: a framework for developing agent-based social simulations', Journal of Artificial Societies and Social Simulation, Vol. 16, No. 2, Publication Number 9.

Ghorbani, A., Dijkema, G.P.J. and Schrauwen, N. (2015) 'Structuring qualitative data for agent-based modelling', Journal of Artificial Societies and Social Simulation, Vol. 18, No. 1, Publication Number 2.

Hardi, E.E., Beumers, P.A. and Geurds, M.J.T. (2011) 'Biogrid; biogas supply through a special distribution grid and adjustment of residential appliances', in International Gas Union Research Conference, Vol. 1 of 4, Curran Associates, New York, USA.

Holland, J.H. (1992) 'Complex adaptive systems', Daedalus, Vol. 121, No. 1, pp.17-30.

Lensink, S.M., Wassenaar, J.A., Mozaffarian, M., Luxembourg, S.L. and Faasen, C.J. (2012) Basisbedragen in de SDE 2013 Eindadvies.

Nikolic, I., van Dam, K. and Kasmire, J. (2012) 'Practice', in van Dam, K., Nikolic, I. and Lukszo, Z. (Eds.): Agent-based Modelling of Socio-technical Systems, pp.73-137, Springer.

Oey, M., Zulkuf, G., Ghorbani, A., Aldewereld, H., Brazier, F., Aydogan, R., Jonker, C.M., Timmer, R. and Wijngaards, N. (2014), 'Modelling multi-stakeholder systems: a case study', in IEEE/WIC/ACM International Joint Conferences on Web Intelligence (WI) and Intelligent Agent Technologies (IAT), pp.404-411.

Ostrom, E. (2000) 'Reformulating the commons', Swiss Political Science Review, Vol. 6, No. 1, pp.29-52.

Ostrom, E. (2005) Understanding Institutional Diversity, Princeton University Press, Princeton.

Scharpf, F. (1997) Games Real Actors Play: Actor-centered Institutionalism in Policy Research, Westview Press, Boulder (CO).

van der Lei, T.E., Bekebrede, G. and Nikolic, I. (2010) 'Critical infrastructures: a review from a complex adaptive systems perspective', International Journal of Critical Infrastructures, Vol. 6, No. 4, pp.380-401.

Velghe, F. and Wierinck, I. (2013) Evaluatie van vergisters in Nederland.

Verhoog, R. (2013) Exploring Biogas Stakeholder Interaction in the Netherlands: An Agent based Modeling Approach to Explore Location Specific Biogas System Performance under Different Scenarios, MSc. thesis, Delft University of Technology.

Wakker, A., van Tilburg, X., Hers, J.S. and Seebregts, A.J. (2006) Elektriciteits-en brandstofprijzen; Achtergrondstudie ter ondersteuning voor onrendabele top berekeningen voor 2008.

Wilensky, U. (1999) NetLogo. Center for Connected Learning and Computer-Based Modeling, Northwestern University, Evanston, IL.

World Bank (2013) World Bank Commodity Forecast Price Data, May 2013 [online] http://knoema.com/WBCFPD2013May (accessed 7 July 2013). 